RESEARCH REPORT

\title{
Social position and minor psychiatric morbidity over time in the British Household Panel Survey 1991-1998
}

\author{
R D Wiggins, P Schofield, A Sacker, J Head, M Bartley
}

J Epidemiol Community Health 2004;58:779-787. doi: 10.1136/jech.2003.015958

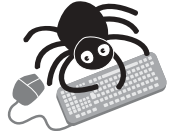

Colour versions of the figures are available on line (http://www.jech. com/supplemental).

See end of article for authors' affiliations

Correspondence to: Professor R D Wiggins, Department of Sociology, Northampton Square, City University, London ECIV $\mathrm{OHB}$, UK; r.d.wiggins@ city.ac.uk

Accepted for publication 16 January 2004
Study objective: To examine social inequalities in minor psychiatric morbidity as measured by the GHQ12 using lagged models of psychiatric morbidity and changing job status.

Design: GHQ scores were modelled using two level hierarchical regression models with measurement occasions nested within individuals. The paper compares and contrasts three different ways of describing social position: income, social advantage and lifestyle (the Cambridge scale), and social class (the new National Statistics Socio-Economic Classification), and adjusts for attrition.

Setting: Survey interviews for a nationally representative sample of adults of working age living in Britain. Participants: 8091 original adult respondents in 1991 who remain of working age during 1991-1998 from the British Household Panel Survey (BHPS).

Main results: There was a relation of GHQ-12 to social position when social position was combined with employment status. This relation itself varied according to a person's psychological health in the previous year.

Conclusions: The relation between social position and minor psychiatric morbidity depended on whether or not a person was employed, unemployed, or economically inactive. It was stronger in those with previously less good psychological health. Among employed men and women in good health, GHQ-12 varied little according to social class, status, or income. There was a "classic" social gradient in psychiatric morbidity, with worse health in less advantaged groups, among the economically inactive. Among the unemployed, a "reverse" gradient was found: the impact of unemployment on minor psychiatric morbidity was higher for those who were previously in a more advantaged social class position.
$\mathrm{T}$ he General Health Questionnaire (GHQ) is a widely used measure of minor psychiatric morbidity, validated and intended for large scale community surveys. ${ }^{1}$ Although most studies using other measures that operationalise depression and psychological function show clear relations to socioeconomic position, studies that use the GHQ show inconsistent results, and most show no social gradient. In this paper we address this puzzle in three ways: by taking a longitudinal perspective that enables us to examine year on year changes in GHQ, by taking account of employment status, and by using three measures of socioeconomic position and circumstances. Data are taken from the British Household Panel Survey (BHPS), which includes the 12 item version of the GHQ every year in its data collection. The BHPS is unique in that we have for the first time GHQ-12 self reports over eight years for the British population. Our analysis focuses on the years 1991, when the study originated, until 1998. We treat the BHPS as a genuine panel study rather than as a series of repeat cross sectional analyses.

\section{BACKGROUND}

Kreiger et $a l^{2}$ argue that there are "diverse aspects and dimensions of $\ldots$ socio-economic position ... [and] ... numerous studies suggest that measures at each level, over time, may be informative." These authors and, more recently, Fryers et $a l^{3}$ make a convincing argument for more precision in the measurement of socioeconomic position and circumstances. Following their plea we examine the relations to mental health of three separately operationalised dimensions of social inequality. These are: the new UK Office for National Statistics socioeconomic classification, the NS-SEC, ${ }^{4}$ a key alternative developed by Prandy and colleagues ${ }^{5}$ that reflects household social advantage and lifestyle (the Cambridge score), and income. The NS-SEC is a measure of occupational social class based on employment relations and conditions, and the Cambridge scale measures general social advantage based on patterns of social mixing and affiliation. In these respects, they attempt to reveal the meaning of social inequality in terms of relationships between individuals in society. In contrast, income only directly reflects a material aspect of social inequality.

Whereas evidence for the relation between minor psychiatric morbidity and social class as measured by the registrar general's schema is weak or inconsistent, ${ }^{36}$ employment status (employed, unemployed, economically inactive), standard of living, and poverty have been shown to be consistently related to minor psychiatric morbidity as measured by the GHQ in a number of studies..$^{7-11}$

Here we report findings for eight waves of BHPS that use all of the information in the GHQ-12 as a continuous outcome, recognise clustering in the data, and focus not only upon income and its relation to GHQ but lifestyle (Cambridge) and employment relations (NS-SEC). We control for a person's job status in any given year, along with their previous year's GHQ score. The loss of information involved in attrition from the panel is also addressed by the use of Schafer's method of data imputation. ${ }^{12}$

\section{SAMPLE AND MEASURES Sample}

Our analysis focuses on 8091 people who were aged between 16 and 64 in 1991, when the study originated, until 1998. For a full description of the sample design and selection probabilities see Taylor et al. ${ }^{13}$ In subsequent modelling we apply cross sectional weights for 1991 to adjust our analyses of imputed data. (see Methods and the appendix for details of our strategy for handling missing data). 


\section{Measures}

\section{Outcome variable}

This was a summative score based upon the 12 item version of the GHQ (GHQ-12) for each wave. Respondents who report any statement (for example, have you recently lost much sleep over worry?) on the scale as applying to them "rather more than usual" or "more than usual" score 1 whereas those reporting "less than usual" or "not at all" score 0 . Summated scores with a value 3 or more (out of 12) are typically used to classify cases of common mental disorder. In our application we use the total score rather than a dichotomy $($ mean $=2.05, \mathrm{SD}=1.99)$.

\section{Person level characteristics}

Age (in years) and sex as recorded in the first wave of the survey, 1991.

\section{Wave or occasion specific characteristics}

Social position was measured at each wave in three ways: the NS-SEC, the Cambridge scale, and income. NS-SEC is a sevenfold categorisation, which classifies occupations according to employment relations and conditions (the degree of job security, opportunity for promotion, work autonomy, and control over the work of others). Economically inactive respondents (for example, retired) were classified according to their last full time occupation. The Cambridge scale was derived from a multidimensional scaling of social distance scores between all pairs of occupations in several field studies undertaken in the UK. The scaling resulted in a single dimension that is labelled "general social advantage and shared lifestyle". Scores reflect the degree to which members of different occupations associated together on a basis of equality. In this analysis it is treated as a household measure where a household is assumed to contain a couple. Whenever this is the case the higher of the individual scores is assigned to the household. In instances where there is no couple present in the household (for example, a shared adult household) individual Cambridge scores are assigned. Income was based upon an adjusted measure of the total gross household income (the Clements's scale ${ }^{14}$ ) to allow for differing needs according household size and composition. To ensure that our comparative analysis used broadly equivalent categorisations of social position we created septiles for the Cambridge scale and our income measure. Allocation to socioeconomic categories is based upon a person's position in each wave for the fully imputed data.
Current economic activity is based on whether or not a person describes themselves as currently employed, unemployed but actively seeking work, or inactive. Previous psychiatric status is simply the previous year's GHQ-12 score referred to in subsequent tables as "GHQ lag". Beyond a one or two year lag there is very little covariance among the multivariate GHQ-outcomes (results not shown). This suggests that a person's current GHQ-12 score is most affected by their immediate history.

\section{METHODS \\ Hierarchical modelling to match the data structure over time}

Hierarchical linear models are appropriate analytical tools to handle panel data where individual sample members generate observations over time. ${ }^{15}{ }^{16}$ Each wave or occasion (level 1 ) is nested within a person at level 2 in the hierarchy. We are able to separate out two simple variance component estimates to describe the variation in GHQ scores. One of these describes the variance between individuals and the other component describes the variance within individuals between occasions of measurement. The variation between individuals can be modelled by including person specific characteristics that are constant throughout the period of the study (for example, sex). The variation within individuals over time can be explained by including circumstances that may change from one measurement occasion to the next (for example, social position, economic activity). The ratio of the between person variance to the total variance is described as the intraunit correlation. It indicates the extent to which our observations are clustered within individuals.

\section{Tackling information loss}

Missing observations have been dealt with by using multiple imputation techniques. ${ }^{12}{ }^{17-21}$ Using 1991 as our sample base only 59\% (4805) of the original respondents remain in the study by 1998 . Another $32 \%$ (2615) leave at any one of the subsequent waves (1992-98) and never return to the study. Others are in the study in 1991, leave in one or more subsequent waves but later return for one or more years. They make up around $8 \%$ (671) of the original sample. If we ignored anyone who is absent from the BHPS in one or more waves we would lose up to $41 \%$ of the original data. Table 1 provides a resume of the extent of attrition. Schafer's $\mathrm{s}^{12}$ data augmentation procedures for filling in provide a full set of data for any pattern of forward missingness (that is, data for anyone who joined the study after 1991 are not imputed). A

Table 1 Patterns of non-response for the BHPS for 1991-98*

\begin{tabular}{lccc}
\hline Monotone patterns & Frequency & Percentage & \\
\hline Complete for all waves & 4805 & 65 & 11111111 \\
1 wave missing & 209 & 3 & 11111110 \\
2 waves missing & 228 & 3 & 11111100 \\
3 waves missing & 223 & 3 & 11111000 \\
4 waves missing & 338 & 5 & 11110000 \\
5 waves missing & 367 & 5 & 11100000 \\
6 waves missing & 487 & 7 & 11000000 \\
7 waves missing & 763 & 10 & 10000000 \\
Total & 7420 & 100 & \\
Non-monotone patterns & Frequency & Percentage & 10111111 \\
1 wave missing & 323 & 48 & 11100111 \\
2 waves missing & 116 & 17 & 11000111 \\
3 waves missing & 72 & 11 & 10000111 \\
4 waves missing & 54 & 8 & 10110000 \\
5 waves missing & 57 & 8 & 10100000 \\
6 waves missing & 49 & 7 & \\
Total & 671 & 100 & \\
\hline \multirow{2}{*}{, present for wave; 0, a drop out for wave. $†$ This illustrates the most frequently occurring combination of this } \\
number of missing waves.
\end{tabular}



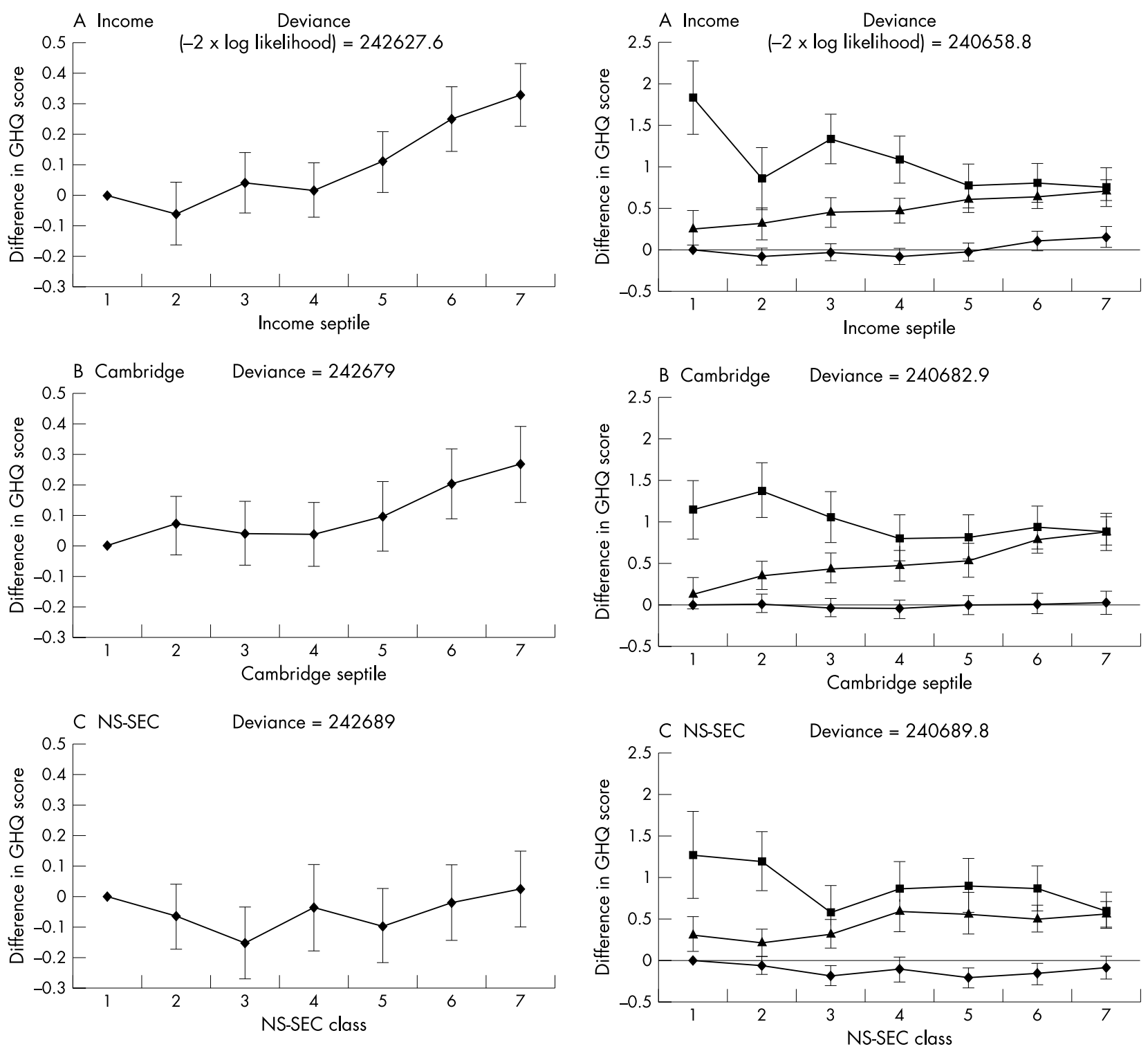

Figure 1 Impact of social position on $G H Q$, controlling for age and sex.

fuller account of the strategy is given in the appendix. For recent applications of Schafer's methodology see Schafer et al, ${ }^{22}$ Schneker et al, ${ }^{23}$ and McCulloch and Joshi. ${ }^{24}$

\section{Modelling strategy}

Analyses are carried out using hierarchical linear modelling ${ }^{25}$ where observations are nested over time within individuals in a two level hierarchy. We adopted a forward selection strategy, conditioning for age and sex (base model) then adding each main effect in turn before testing for two and three way interactions. All models are simple variance component models, which are fitted using the panel data functions for longitudinal data available in Stata (release 6.0, College Station, TX).

All figures (fig 1, 2, 3, and 4) and analyses (tables 2-7) show predicted GHQ scores based on augmented data.

\section{RESULTS}

Augmentation procedures have brought the distributions in the BHPS sample available for analysis closer to that of the population of UK as reflected in 1991 census data (see appendix table $\mathrm{Al}$ ).

Figure 2 Impact of social position on $G H Q$, controlling for job status, age, and sex.

Table 2 shows the marginal frequencies for each measure of socioeconomic position and circumstances: NS-SEC, Cambridge, and household income after data augmentation. The first category in each measure represents the highest level of income or prestige.

Table 3 summarises the mean GHQ score by economic activity after imputation. The unemployed have a marginally higher score than the economically inactive although the unemployed outnumber the economically inactive by about 4:1.

Table 4 presents the initial modelling in terms of our null model that contains no explanatory variables but shows the amount of variation at occasion and individual levels, and a base model where age and sex controls are entered. As evidenced by the intraunit correlation coefficients ( $\rho$ values) in the null model there is a clear confirmation that there is a substantial amount of within person wave on wave variation in GHQ scores as well as between person variance to explain $(\rho=0.38)$. Adding controls for sex and age produces a modest reduction in the between persons variance (about 3\%, 2.89 compared with 2.81), and no reduction in the amount of within person wave on wave variance left to explain. 

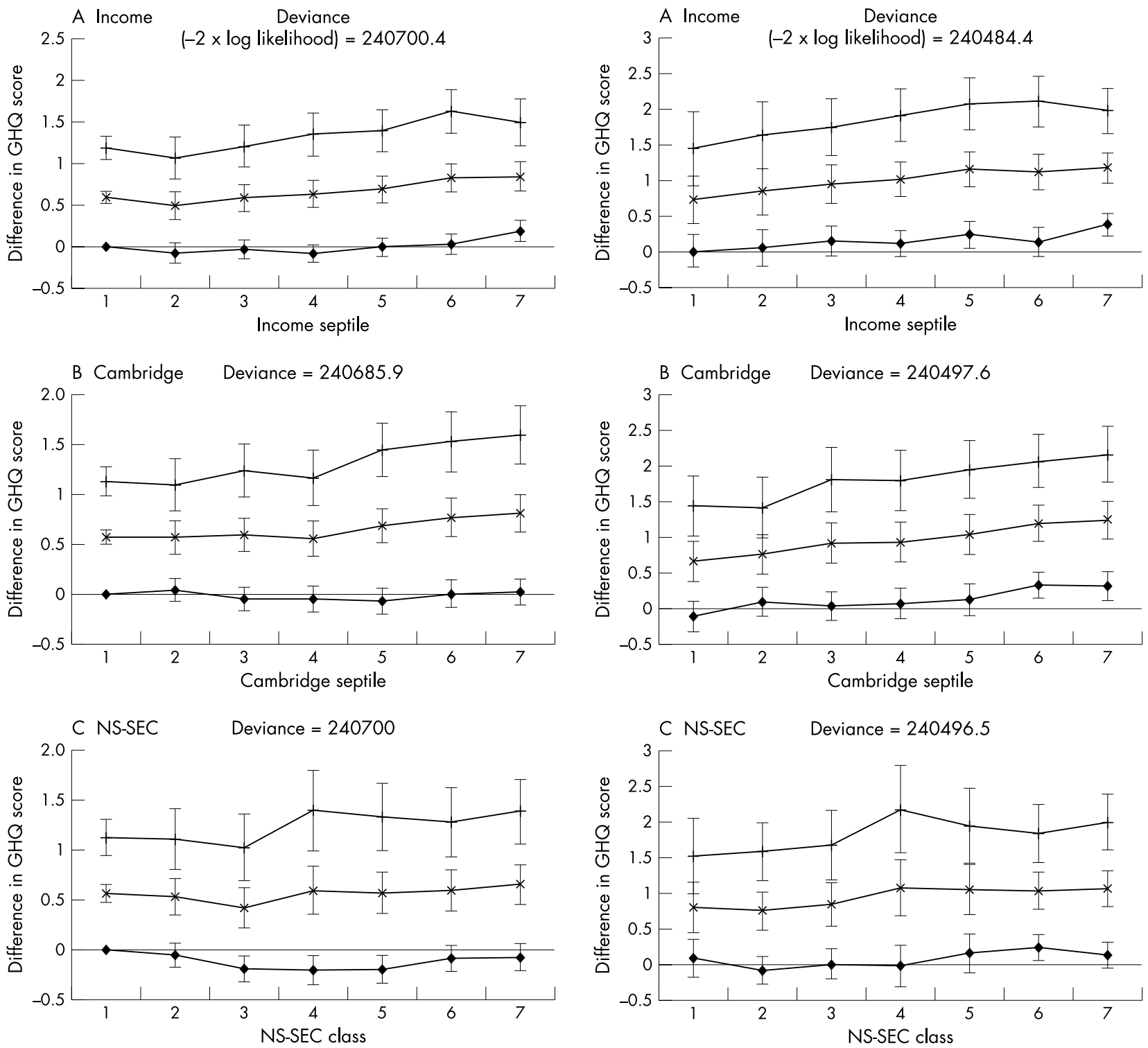

Figure 3 Impact of social position on GHQ, controlling for ghq-lag, age, and sex.

Next we include each measure of social position in turn at the wave level to examine the impact on the base model. Table 5 shows the relative reduction in the variance components. Social position, however measured, explains a negligible amount of the wave on wave variation. Nor does the introduction of the measures of social position explain any great amount of the between person differences. If anything knowing a person's income level is comparatively more informative than knowing their social status as measured by the Cambridge scale or their social class based on employment relations using NS-SEC.

Although the measures of socioeconomic position do not explain a great deal of the variance in GHQ scores, turning to the fixed part of these models in figure 1 we can see some evidence of a gradient of predicted GHQ scores for two of the measures. This figure as with all subsequent figures shows the predicted difference in the GHQ score above and below the reference category for each measure of social position (always the most advantaged group).

Broadly, GHQ levels rise as income levels decline, with a similar but shallower gradient as Cambridge levels fall. For NS-SEC there is some weak evidence for a relation. The

Figure 4 Impact of social position on $G H Q$, controlling for ghq-lag, age, and sex for the "ever economically inactive".

difference between the most advantaged groups (septile 1) and the least advantaged (septile 7) is never more than a third of a GHQ point. Notably, the relative rise in GHQ for SEC 4 (self employed and small employers) in relation to their nearest neighbours could mark the risk of a relatively higher GHQ score in the self employed.

The addition of economic activity status and prior health (GHQ lag) adds considerably to the explanatory power of the models. From table 6 we see that a person's current job status results in a further modest reduction in between person variance (about 3\%) whereas a person's previous year's GHQ score reduces the between person variance considerably (about $48 \%$ ). The inclusion of GHQ lag also indicates a modest increase $(4.6 \%)$ in the within person wave on wave variance.

For the impact of job status and GHQ lag as main effects in the model examine figures 2 and 3. Figure 2 shows that GHQ scores are lowest for the employed, highest for the unemployed, and intermediate for the inactive. It also shows that gradients according to socioeconomic position differ according to employment status. For the employed the gradients are virtually flat. In the inactive, GHQ scores are higher in those in less advantaged socioeconomic position according to all 
Table 2 Distribution of socioeconomic position measures: augmented data*

\begin{tabular}{|c|c|c|}
\hline Income septile & Frequency & Percentage \\
\hline 1 & 8918 & 17.23 \\
\hline 2 & 8559 & 16.53 \\
\hline 3 & 8173 & 15.79 \\
\hline 4 & 7618 & 14.71 \\
\hline 5 & 6676 & 12.90 \\
\hline 6 & 5593 & 10.80 \\
\hline 7 & 6234 & 12.04 \\
\hline \multicolumn{3}{|l|}{ Cambridge septile } \\
\hline 1 & 7649 & 14.77 \\
\hline 2 & 7567 & 14.62 \\
\hline 3 & 7459 & 14.41 \\
\hline 4 & 7410 & 14.31 \\
\hline 5 & 7274 & 14.05 \\
\hline 6 & 7303 & 14.11 \\
\hline 7 & 7110 & 13.73 \\
\hline \multicolumn{3}{|l|}{ NS-SEC } \\
\hline $\begin{array}{l}\text { Higher managerial and } \\
\text { professional }\end{array}$ & 5678 & 10.97 \\
\hline $\begin{array}{l}\text { Lower managerial and } \\
\text { professional }\end{array}$ & 11031 & 21.31 \\
\hline Intermediate occupations & 7674 & 14.82 \\
\hline $\begin{array}{l}\text { Small employers and own } \\
\text { account }\end{array}$ & 5053 & 9.76 \\
\hline $\begin{array}{l}\text { Lower supervisory and } \\
\text { technical }\end{array}$ & 5337 & 10.31 \\
\hline Semi-routine occupations & 8603 & 16.62 \\
\hline Routine occupations & 8396 & 16.22 \\
\hline Total & 51772 & 100.00 \\
\hline
\end{tabular}

*All marginal frequencies have been reweighted using wave one (1991) cross sectional weights.

three measures. However, the differential between the most and least advantaged is rarely greater than half a GHQ point. But the relative impact of unemployment for who were previously high earners and experienced more favourable employment relations (along the NS-SEC dimension) suggests a reverse gradient. Here the most advantaged rise almost a whole GHQ point above their counterparts. The gradient for the unemployed along the dimension of household prestige (Cambridge scale) is less evident.

Figure 3 shows the impact of a person's previous year's GHQ score. Three GHQ scores have been used to illustrate the impact of the previous year's score. For those with no previous GHQ symptoms (always the majority in any wave) there is no social gradient. As previous year's GHQ scores rise we begin to see some evidence of a gradient by socioeconomic position with notable "humps" at higher levels for the small employers and self employed (as defined by the NS-SEC) where their previous year's GHQ score was high. Although the impact of a relatively high GHQ score in the previous year never pushes the current score much above half a point for the least advantaged.

The final stage in our modelling combines the effect of socioeconomic position and economic activity status on GHQ in each year controlling for the previous year's GHQ score. For each measure of social position, three way interactions

Table 3 Mean GHQ score by economic activity augmented data*

\begin{tabular}{lccl}
\hline Job status & Frequency & Percentage & Mean GHQ \\
\hline Employed & 37122 & 71.70 & 1.83 \\
Unemployed & 2468 & 4.77 & 2.70 \\
Inactive & 12182 & 23.53 & 2.59 \\
Total & 51772 & 100.00 & 2.05 \\
\hline
\end{tabular}

${ }^{*}$ All estimates are adjusted using wave one (1991) cross sectional weights.
Table 4 Variance components for null and base models, augmented data (base model includes age and sex only)*

\begin{tabular}{llll}
\hline & \multicolumn{2}{l}{ Variance } & \\
\cline { 2 - 3 } & Level 2 & Level 1 & p† \\
\hline Null & 3.03 & 5.02 & 0.38 \\
Base & 2.94 & 5.02 & 0.37 \\
\hline
\end{tabular}

*All estimates are adjusted using wave one (1991) cross sectional weights. tIntraunit correlation.

Table 5 Relative variance component reduction for social position models over the base model*

\begin{tabular}{|c|c|c|c|}
\hline \multirow[b]{2}{*}{ Social position measure } & \multicolumn{2}{|c|}{$\begin{array}{l}\text { Percentage reduction in } \\
\text { variance }\end{array}$} & \multirow[b]{2}{*}{$\boldsymbol{\rho}$} \\
\hline & Level 2 & Level 1 & \\
\hline Income & 1.02 & 0.00 & 0.37 \\
\hline Cambridge & 0.34 & 0.00 & 0.37 \\
\hline NS-SEC & 0.00 & 0.00 & 0.37 \\
\hline
\end{tabular}

between social position, job status, and the GHQ lag score were statistically significant. Thus to interpret the relation between social position and GHQ scores we have to simultaneously take account of current economic activity status and a person's previous GHQ score as well as their age and sex. Table 7 summarises the predicted change in GHQ score for persons of average age with one of two hypothetical GHQ scores in the previous year (zero and 3) based on these models. At all combinations of levels of job status, social position, and previous year's GHQ score, women tend to have a higher reported GHQ score than men of the same age (about half a point higher). The interaction between job status and the previous year's GHQ score shows evidence of a greater effect of social position in economically inactive persons who had a high GHQ score in the previous year. As a result we concentrate on the economically inactive in figure 4.

Figure 4 focuses on the relation of social position measures to GHQ score in men and women only at a time when they were economically inactive. It shows that even in this group, the presence of a social gradient depended on their psychological health in the previous year. In those without any GHQ symptoms in the previous year there is little to no evidence of a social gradient in GHQ. There is slight evidence along the income and Cambridge scale dimensions for higher scores among those in the bottom two septiles. Beyond that, clearer gradients are seen along the prestige dimension (Cambridge scale), the higher the level of reported GHQ in the previous year. Apart from a downturn for the lowest septile this is supported along the income scale. For NS-SEC we see similar amounts of relative increase as the previous year's GHQ scores become higher. Again, small employers and self employed (SEC 4) among those currently inactive

Table 6 Relative variance component reduction for job status and lagged GHQ score over the base model*

\begin{tabular}{lccc}
\hline & \multicolumn{2}{c}{ Percentage reduction in variance } \\
\cline { 2 - 3 } & Level 2 & Level 1 & P \\
\hline Job status & 3.06 & 0.40 & 0.36 \\
GHQ lag & 47.96 & -4.58 & 0.23 \\
\hline *All estimates are adjusted using wave one (1991) cross sectional \\
weights.
\end{tabular}


Table 7 Relation of occasion specific social position measures to GHQ score for final models conditional upon a one year lag for GHQ scores of 0 and 3 (for illustration) and controlling for age and sex

\begin{tabular}{|c|c|c|c|c|c|c|c|c|c|}
\hline \multirow{2}{*}{$\begin{array}{l}\text { Economic } \\
\text { status }\end{array}$} & \multirow{2}{*}{$\begin{array}{l}\text { Socioeconomic position } \\
\text { NS-SEC }\end{array}$} & \multicolumn{2}{|c|}{$\begin{array}{l}\text { Previous year's } \\
\text { GHQ }\end{array}$} & \multirow{2}{*}{$\begin{array}{l}\text { Socioeconomic } \\
\text { position }\end{array}$} & \multicolumn{2}{|c|}{$\begin{array}{l}\text { Previous year's } \\
\text { GHQ }\end{array}$} & \multirow{2}{*}{$\begin{array}{l}\text { Socioeconomic } \\
\text { position }\end{array}$} & \multicolumn{2}{|c|}{ Previous year's GHQ } \\
\hline & & 0 & 3 & & 0 & 3 & & 0 & 3 \\
\hline \multirow[t]{7}{*}{ Employed } & $\begin{array}{l}\text { Higher managerial } \\
\text { and professional }\end{array}$ & 0.000 & 0.513 & 1 & 0.000 & 0.511 & 1 & 0.000 & 0.565 \\
\hline & $\begin{array}{l}\text { Lower managerial and } \\
\text { professional }\end{array}$ & -0.031 & 0.479 & 2 & -0.005 & 0.455 & 2 & -0.090 & 0.440 \\
\hline & Intermediate & -0.197 & 0.306 & 3 & -0.098 & 0.443 & 3 & -0.086 & 0.478 \\
\hline & $\begin{array}{l}\text { Small employer and } \\
\text { self employed }\end{array}$ & -0.197 & 0.440 & 4 & -0.126 & 0.385 & 4 & -0.135 & 0.485 \\
\hline & Lower technical and supervisory & -0.271 & 0.393 & 5 & -0.180 & 0.495 & 5 & -0.068 & 0.486 \\
\hline & Semi-routine & -0.186 & 0.370 & 6 & -0.157 & 0.500 & 6 & 0.053 & 0.622 \\
\hline & Routine & -0.138 & 0.448 & 7 & -0.118 & 0.447 & 7 & 0.155 & 0.560 \\
\hline \multirow[t]{7}{*}{ Unemployed } & $\begin{array}{l}\text { Higher managerial and } \\
\text { professional }\end{array}$ & 0.819 & 1.747 & 1 & 0.893 & 1.478 & 1 & 1.429 & 2.204 \\
\hline & $\begin{array}{l}\text { Lower managerial and } \\
\text { professional }\end{array}$ & 0.853 & 1.548 & 2 & 0.661 & 1.591 & 2 & 0.811 & 1.228 \\
\hline & Intermediate & 0.408 & 1.075 & 3 & 0.496 & 1.630 & 3 & 1.307 & 1.971 \\
\hline & $\begin{array}{l}\text { Small employer and } \\
\text { self employed }\end{array}$ & 0.184 & 1.362 & 4 & 0.700 & 1.185 & 4 & 0.914 & 1.663 \\
\hline & Lower technical and supervisory & 0.647 & 1.443 & 5 & 0.621 & 1.271 & 5 & 0.429 & 1.209 \\
\hline & Semi-routine & 0.459 & 1.503 & 6 & 0.589 & 1.345 & 6 & 0.329 & 1.309 \\
\hline & Routine & 0.505 & 1.005 & 7 & 0.395 & 1.341 & 7 & 0.393 & 1.191 \\
\hline \multirow[t]{7}{*}{ Inactive } & $\begin{array}{l}\text { Higher managerial and } \\
\text { professional }\end{array}$ & 0.086 & 0.805 & 1 & -0.111 & 0.666 & 1 & 0.018 & 0.735 \\
\hline & $\begin{array}{l}\text { Lower managerial and } \\
\text { professional }\end{array}$ & -0.074 & 0.757 & 2 & 0.098 & 0.760 & 2 & 0.061 & 0.851 \\
\hline & Intermediate & 0.015 & 0.847 & 3 & 0.032 & 0.922 & 3 & 0.157 & 0.954 \\
\hline & $\begin{array}{l}\text { Small employer and } \\
\text { self employed }\end{array}$ & -0.014 & 1.083 & 4 & 0.071 & 0.936 & 4 & 0.125 & 1.021 \\
\hline & Lower technical and supervisory & 0.163 & 1.055 & 5 & 0.123 & 1.040 & 5 & 0.246 & 1.162 \\
\hline & Semi-routine & 0.239 & 1.039 & 6 & 0.332 & 1.201 & 6 & 0.140 & 1.126 \\
\hline & Routine & 0.136 & 1.069 & 7 & 0.318 & 1.243 & 7 & 0.381 & 1.182 \\
\hline
\end{tabular}

Estimates are for a person of average age in 1991 (38 years) and include a main effect for sex (between 0.36 and 0.38 ) and GHQ-lag of 0.19 for models that use income for social position and around 0.17 for the NS-SEC and Cambridge models.

and having previously high levels of GHQ peak above any of the other NS-SEC positions.

\section{DISCUSSION AND CONCLUSION}

As the availability and richness of longitudinal data on the social determinants of health increase rapidly, methods similar to those we adopt in this paper are beginning to be extended to social epidemiological studies outside the field of health inequality. Panel data have the potential to improve our ability to test the causal nature of observed associations by demonstrating dose-response relations over time. However, they present two major challenges. The first of these is how best to exploit long sequences of events, in which individuals move in and out of conditions in contrast with conventional survival analysis. The second is the issue of sample attrition.

Most recently Weich et $a^{26}$ analysed BHPS data using the first seven waves of data to examine the effect of social roles and gender differences on mental health assessed using the GHQ. Their analytical strategy addresses both of these challenges. Firstly, they analyse the sequences of GHQ scores by treating observations as clustered over time within individuals and using random effects models. ${ }^{27}$ This is equivalent to the hierarchical modelling we have adopted via simple variance component modelling in Stata. Secondly, they tackle the problem of attrition by analysing those participants aged $16-70,(\mathrm{n}=9947)$, who answered the GHQ on at least two consecutive occasions. Our preference has been to fill in or augment the wave by case data matrix before our analyses using multiple imputation for the whole person by year matrix rather than condition upon consecutive pairs of observations. This encouraged us to extend a similar approach to inequalities in mental health.
The approach has several advantages. One is that it can allocate variation in mental health as between the effects of varying social and economic circumstances within the same person, and the effect of characteristics that distinguish individuals throughout the period of observation. Over $20 \%$ of the variance in minor psychiatric morbidity in this sample of the British population was shown to be explained in terms of time varying social and economic circumstances over the eight year period, and only $1.2 \%$ in terms of stable individual characteristics. In this paper we have been concerned to show the way this approach may be applied to the study of health inequality, and have for simplicity only examined a very limited number of both time invariant individual and time varying factors: there is obvious scope for exploring more elaborated models.

There is a perennial problem in health inequality research that associations between social conditions and health may result from the effect of health itself on, for example, income ("selection"). In the approach we have taken there are two safeguards to this. The first is that the method assumes that the employment statuses, socioeconomic positions, and health statuses of any person over time are not totally independent events but will tend to "cluster". The method used in this paper makes it quite feasible for future work to try and explain the stability or "state dependence" of individual work histories in terms of hypothetically time invariant level 2 characteristics such as educational ability or childhood experiences. The second way in which we have addressed the problem of selection is by the use of a one year lag in the GHQ. This decision was supported by an empirical evaluation of the inter-relations between the successive GHQ scores for each wave by treating them as a set of multivariate outcomes nested within each person. ${ }^{15}$ Beyond a one year lag covariance estimates between GHQ scores were weak. 


\section{Key points}

- Using the GHQ-12 for the first eight years of the BHPS we have been able to show the way in which variation in mental health can be attributed in part to the effects of varying social and economic circumstances within the same individual, and in part to the effect of characteristics that distinguish individuals

- The relation of socioeconomic position and circumstances to minor psychiatric morbidity depends upon whether or not a person is employed, unemployed, or economically inactive

- Social inequality has a different effect according to a person's mental health a year ago

- The relation of advantage and disadvantage, however measured, is greater in those with previously less good health

- For the unemployed there is evidence of a sharp "reverse" gradient whose previous jobs were more advantaged

- For the economically inactive there is evidence of a social gradient in mental health

- Among the economically inactive, women report higher levels of psychological distress in every socioeconomic category

Indeed, GHQ score in the previous year was found to be by far the strongest explanation of GHQ score in any current year. However, lagged GHQ did not explain away the relation of socioeconomic position to current GHQ. Rather, the results show that social inequality has a different effect according to mental health one year ago. If anything the relation of advantage and disadvantage, however measured, is greater in those with previously less good health.

The interaction between socioeconomic position and employment status is in some ways a very surprising result, but it is in fact consistent with previous literature. The impact of unemployment on mental health may depend on the extent of "relative deprivation" produced by job loss. ${ }^{28-30}$ Platt and Kreitman ${ }^{31}$ also found that the relative risk of parasuicide among the unemployed was higher in middle class than working class areas. This is consistent with the very high rates of GHQ caseness found here among unemployed persons in more advantaged households and who had previously been in more socially advantaged occupations as measured by the NS-SEC.

In sharp contrast with unemployment, economic inactivity (the employment status of retirement, permanent sickness, or full time home care) appears to amplify the effect of socioeconomic position on mental health as measured by the GHQ. Taken together with a person's immediate GHQ history, it does seem that in this group relative income will afford some protection against a high GHQ score in the current year. This is in line with the findings of previous studies that have found relations of GHQ to poverty and deprivation. However in this study, the risk of a high GHQ score was also increased throughout the lowest three septiles of the income distribution, not only in the poorest.

It seems that it is in the economically inactive group that low household income or prestige have the most significantly deleterious effect on mental health, particularly on the ability to recover from poor health in the previous year (interaction of lagged GHQ with socioeconomic position measure among the inactive). This result applies most strongly to the women in the sample: some $45 \%$ of all the person years of economic inactivity in the eight years of observation were experienced by women in the form of home care. It is well known that women without paid employment tend to have poorer mental health than those with jobs. ${ }^{31-33}$ However, the social gradient seen in this group is not often commented upon.

The large amount of within person variation over short to medium term spans means that a high GHQ score in any one year does not necessarily imply continued high levels of this type of psychological distress. This paper has shown that to understand the part played by changes in socioeconomic position and economic status in changes in psychological health, consideration must be given to ways in which these experiences interact, and how their effects are influenced by pre-existing psychological health.

\section{ACKNOWLEDGEMENTS}

The authors wish to express their thanks to colleagues in the MRC team at UCL, notably Dr Tarani Chandola and Dr Paul Clarke.

\section{Authors' affiliations}

A Sacker, J Head, M Bartley, Department of Epidemiology and Public Health, University College, London, UK

P Schofield, The Institute of Psychiatry, University of London, UK R D Wiggins, Department of Sociology, City University, London, UK

Funding: this work was funded as part of the Medical Research Council's "Health of the Public" initiative. Grant number: 9900586.

Conflicts of interest: none declared.

\section{APPENDIX}

\section{MORE ON TACKLING INFORMATION LOSS}

Any prospective subject loss has been managed by treating the person year dataset as a series of case observations across time. This allows the analyst to use multiple imputation to fill in any missing observations. ${ }^{12}$ The analytical model is then applied to each filled in dataset in turn, and the parameter estimates averaged using the appropriate formulas. This strategy gives parameter estimates adjusted for non-response bias (under certain assumptions that will be discussed further on) and maximises the amount of information available for analysis. An alternative approach to adjust for non-response bias would be to use one of the weighting schemes routinely available with the BHPS. The longitudinal weights "gross up" estimates based on those individuals who have complete data across all waves (caaw), and the cross sectional weights gross up those who have complete data within waves (cww). Analyses are reasonably straightforward to apply using Stata but a substantial proportion of information from incomplete cases is lost from the analysis.

In this paper, the multiple imputation method of Schafer is used. ${ }^{12}$ Schafer's approach fills in missing values using a procedure, which adjusts for non-response bias provided that (a) the survey variables follow a multivariate normal distribution and (b) the data are "missing at random" (MAR). (De Leeuw et $a^{20}$ contains a useful description of missing data mechanisms and treatment strategies.) Essentially, any "gap" or block of missing items in a longitudinal record is filled in. Of course, this might represent a whole year's set of observations. The analyst then conducts whatever analysis is planned over a number of filled in data replicates. The recommended number of replicates arises from Little and Rubin's ${ }^{34}$ work on multiple imputation. The actual number is decided upon by the extent of missingness in our rectangular person by year matrix. This is equivalent to the percentage of missing data entries (case by variable) to the total number of entries if the whole matrix were complete ( around 24\% for our data). This suggests that we use five replicates to achieve around 95\% efficiency. Final parameter estimates 
Table A1 Age by sex percentage distributions (using weighted and unweighted BHPS data, compared with 1991 census data)

\begin{tabular}{|c|c|c|c|c|c|c|c|c|c|}
\hline \multirow[b]{2}{*}{ agecat } & \multicolumn{3}{|c|}{ BHPS 1991 unweighted } & \multicolumn{3}{|c|}{ BHPS 1991 weighted } & \multicolumn{3}{|c|}{ Census 1991} \\
\hline & Male & Female & Total & Male & Female & Total & Male & Female & Total \\
\hline $16-24$ & 9.5 & 9.1 & 18.6 & 9.9 & 9.9 & 19.8 & 10.5 & 9.9 & 20.4 \\
\hline $25-34$ & 11.9 & 13.5 & 25.4 & 11.8 & 12.1 & 23.9 & 12.0 & 12.4 & 24.4 \\
\hline $35-44$ & 10.5 & 12.1 & 22.6 & 10.9 & 11.0 & 21.8 & 10.5 & 10.8 & 21.3 \\
\hline $45-54$ & 8.8 & 10.0 & 18.9 & 9.2 & 9.2 & 18.4 & 9.0 & 9.1 & 18.1 \\
\hline $55-64$ & 6.9 & 7.6 & 14.5 & 7.9 & 8.3 & 16.2 & 7.5 & 8.3 & 15.8 \\
\hline Total & 47.7 & 52.3 & 100.0 & 49.6 & 50.4 & 100.0 & 49.5 & 50.5 & 100.0 \\
\hline
\end{tabular}

(for example, regression coefficients) in subsequent regression modelling are then averaged across the replicates and corresponding standard errors are calculated using Rubin's rule. Typically, standard errors will be larger than those obtained by simply analysing those cases with complete records because they are inflated to account for uncertainty about the filled in values. The multiple imputation algorithm, applied before analysis, is that implemented in the free software NORM, which assumes that the data is multivariate normally distributed as well as any missingness being MAR. Survey variables with continuous, non-normally distributed outcomes were transformed to normality; filled in values for categorical outcome variables were truncated to the nearest integer value. ${ }^{*}$ To be included in our analysis someone has to be present in the BHPS in the year of the study's origin, 1991. Analyses for the filled in datasets are then simply adjusted by applying the cross sectional weights for that year as routinely supplied by BHPS. ${ }^{13}$ These weights bring the observed sample in line with 1991 population distributions based on the census. Table Al shows how well this procedure works for age and sex distributions.

In modelling analyses (not presented) we adopted two strategies that did not entail any multiple imputation. The first simply uses those 8091 cases that have complete sets of observations within any wave or year (complete within wave or (ww). These data can be handled routinely under hierarchical linear modelling procedures. The second approach would simply be to apply the longitudinal weights provided by the BHPS to those 4805 cases who have complete observations across all eight waves (caaw). Essentially, a longitudinal weight is a composite of many sub-categories of data that are "best" predictors of loss (personal communication). In terms of assumptions about missingness this would be equivalent to assuming that items were "missing completely at random" (MCAR) in the subclass defined by the longitudinal weight. We judge Schafer's approach to be an improvement over this approach because it does not assume that the missing people in a subclass are simply a random sample of people in that subclass. Under MAR missing values are assumed to depend on the values of the

*Procedures to routinely handle categorical data are not available as freeware. characteristics of those for whom we do have observations and not on the characteristics that they share in common. In pragmatic terms a filled in dataset resulting from our MAR based imputation results in a dramatic gain over caaw (a 68\% increase in available data: 323640 (8091 cases $\times 8$ waves $\times 5$ items) data points compared with $192200(4805 \times 8 \times 5)$ under caaw). Whereas the cww analysis represents a compromise that draws upon 251980 data points or a $31 \%$ gain over caaw). Following Schafer and Graham ${ }^{35}$ we are inclined to trust our MAR based analysis, which does appear to be supported by the data. Firstly, the pre-imputation and postimputation results are sensible: post-imputation mean GHQ scores are higher than pre-imputation scores, which suggests that those who have missing data tend to be in lower social positions and non-employed (table A2). Secondly, it is unlikely that the reasons for drop out or compliance for any item are solely related to GHQ status alone.

Schafer and Graham investigated drop out in a survey of drug use where it was postulated that the data on drug use were "missing not at random" (MNAR), and so NORM would give biased results. However, they found that, while drop out depended strongly on factors associated with drug use, these factors were also strongly associated with survey variables with high response rates, and so the MAR assumption was valid. We subscribe to their view that this is the exception rather than the rule with rich social surveys.

In Results, findings are presented for the augmented dataset alone (averaged across five replicates). Comparing the caaw and cww models with the models based on augmented or filled in data we see a consistent disparity in the value of the intraclass class correlation around 0.20 for the first compared with 0.22 for the second. This suggests that by ignoring those with incomplete or partial data we will overemphasise the power of the final model to explain both the variance in GHQ scores between individuals as well as that within individuals over time. Secondly, the relative magnitude of the variances for the between individual component (level 2) compared with the within individual component (level 1) tends to shift. Filled in models tend to account for relatively more of the within individual level variance whereas the caaw and cww models show a consistently smaller between individuals component. This might tentatively be interpreted in terms of greater homogeneity

A2 Pre-imputation and post-imputation means for GHQ (unweighted data)

\begin{tabular}{llllll}
\hline & \multicolumn{2}{l}{ Pre-imputation GHQ mean } & & \multicolumn{2}{l}{ Post-imputation GHQ mean } \\
\cline { 2 - 3 } \cline { 5 - 6 } Missing waves* & Mean & Frequency & & Mean & Frequency \\
\hline None missing & 1.92 & 37509 & & 1.93 & 38439 \\
One or more missing & 1.89 & 10926 & & 2.17 & 23005 \\
Overall mean and & 1.91 & 48435 & & 2.02 & 61444 \\
frequency & & & & \\
\hline
\end{tabular}

*Complete waves will invariably include item non-response. This explains the discrepancy in the wave by case frequency for post-imputation mean where there are no waves missing. 
among loyal responders. Among the fixed effects gender reflects a consistent difference that is, interestingly, relatively stronger for the complete cases across all waves data $(0.46$ compared with 0.38 ). Otherwise the pattern of fixed effects is reasonably consistent although, augmented data analyses produce three way terms with consistently smaller coefficients. This would tend to render our conclusions to be relatively more conservative than they would be if based on fewer cases over time.

\section{REFERENCES}

1 Goldberg D, Williams $P$. The user's guide to the general health questionnaire. Windsor: NFER-NELSON, 1988.

2 Kreiger N, Williams DR, Moss NE. Measuring social class in US public health research. Annu Rev Public Health 1998;18:341-78.

3 Fryers T, Meltzer D, Jenkins R. Social inequalities and the common mental disorders: a systematic review of the evidence. Soc Psychiatry Psychiatr Epidemiol 2003;38:229-37.

4 Rose D, O'Reilly K. Constructing classes. Swindon: Economic and Social Research Council with Office for National Statistics, 1997.

5 Prandy K. The revised Cambridge scale of occupations. Sociology 1990;24:629-55.

6 Department of Health. Health survey for England. London: Department of Health, 1998.

7 Weich S, Lewis G. Material standard of living, social class and the prevalence of the common mental disorders in Great Britain. J Epidemiol Community Health 1998;52:8-14.

8 Benzeval M, Judge K. Income and health: the time dimension. Soc Sci Med 2001:52:1371-90.

9 Stansfeld SA, Marmot MG. Social class and minor psychiatric disorder in British civil servants: a validated screening survey using the general health questionnaire. Psychol Med 1992;22:739-49.

10 Weich S, Lewis G. Poverty, unemployment and common mental disorders: population based cohort study. BMJ 1998;317:115-18.

11 Lewis G, Bebbington P, Brugha T, et al. Socioeconomic status, standard of living, and neurotic disorder. Lancet 1998;352:605-9.

12 Schafer JL. The analysis of incomplete multivariate data. London: Chapman Hall, 1997.

13 Taylor MF, Brice J, Buck N, et al. British Household Panel Survey user manual. Volume A: introduction, technical report and appendices. Colchester: University of Essex, 2001.

14 Department of Social Security. Households below average income. London: HMSO, 1992.

15 Goldstein H. Multilevel models in educational and social research. Oxford: Oxford University Press, 1997.

16 Leyland AH, Goldstein H, eds. Multilevel modelling of health statistics. Chichester: Wiley, 2001.
17 Rubin DB. Multiple imputation for nonresponse in surveys. New York: Wiley, 1987.

18 Schafer JL, Olsen MK. Multiple imputation for multivariate missing-data problems: a data analyst's perspective. Multivariate Behavior Research 1998;33:545-71.

19 Wiggins RD, Ely M, Lynch K. A comparative evaluation of currently available software remedies to handle missing data in the context of longitudinal design and analysis. Social science methodology in the new millennium. Proceedings for 5th international conference on logic and methodology, Cologne, 2000.

20 Leeuw EDde, Hox J, Huisman M. Prevention and treatment of item nonresponse. Journal of Official Statistics 2003;19:153-76.

21 Raghunathan TE, Reiter JP, Rubin DB. Multiple imputation for statistical disclosure limitation. Journal of Official Statistics 2003;19:1-16.

22 Schafer JL, Ezzaati-Rice YM Johnson W, et al. The NHANES III multiple imputation project. Technical report. Washington: The US National Centre for Health Statistics, 1996.

23 Schneker N, Raghunathan TE, Pei-Lu C, et al. Multiple imputation of missing income and earnings items in the National Health Interview Survey. Technical Report. Michigan: Institute for Social Research, University of Michigan, 2002.

24 McCulloch A, Joshi HE. Child development and family resources: evidence from the second generation of the 1958 British birth cohort. Journal of Population Economics 2002;15:283-304.

25 Bryk AS, Raudebush S. Hierarchical linear models. Newbury Park, CA: Sage, 1992.

26 Weich S, Sloggett A, Lewis G. Social roles and gender difference in rates of the common mental disorders in Britain: a 7 year population based cohort study. Psychol Med 2001;31:1055-64.

27 Diggle PJ, Liang K-Y, Zeger SL. Generalized linear models for longitudinal data. In: Analysis of longitudinal data. Oxford: Oxford University Press, 1994:131-45.

28 Winefield AH, Tiggeman M, Goldney RD. Psychological concomitants of satisfactory employment and unemployment in young people. Soc Psychiatry Psychiatr Epidemiol 1988;23:149-57.

29 Winefield AH, Tiggeman M, Goldney RD. The psychological impact of unemployment and unsatisfactory employment in young men and women: longitudinal and cross-sectional data. Br J Psychol 1991;82:473-80.

30 Burchell B. Who is affected by unemployment? Job insecurity and labour market influences on psychological health. In: Gallie D, Marsh C, Vogler C, eds. Unemployment and social change. Oxford: Oxford University Press, 1996.

31 Platt S, Kreitman N. Parasuicide and unemployment among men in Edinburgh 1968-1982. Psychol Med 1985;15:113-23.

32 Rosenfield S. The effects of women's employment: personal control and sex differences in mental health. J Health Soc Behav 1989;30:77-91.

33 Elliott BJ, Huppert FA. In sickness and in health: associations between physical and mental well-being, employment and parental status in a British nationwide sample of married women. Psychol Med 1991;21:515-24.

34 Little RJ, Rubin DB. Statistical analysis with missing data. Chichester: Wiley, 1987.

35 Schafer JL, Graham JW. Missing data: our view of the state of the art. Psychological Methods 2002;7:147-77. 


\section{PostScript}

\section{LETTERS}

If you have a burning desire to respond to a paper published in the JECH, why not make use of our "rapid response" option?

Log on to our website (www.jech.com), find the paper that interests you, and send your response via email by clicking on the "eletters" option in the box at the top right hand corner.

Providing it isn't libellous or obscene, it will be posted within seven days. You can retrieve it by clicking on "read eletters" on our homepage.

The editors will decide as before whether to also publish it in a future paper issue.

\section{Relation of rainfall pattern and epidemic leptospirosis in the Indian state of Kerala}

Leptospirosis epidemics in tropical countries are often related to heavy rainfall and flooding. ${ }^{1-4}$ The Indian state of Kerala has witnessed post-monsoon epidemics of leptospirosis in recent years. We investigated the relation between the pattern of daily rainfall and the incidence of disease in Calicut, North Kerala by plotting the number of confirmed cases having onset of illness on each day with the daily rainfall recorded for the district by the state meteorology department between July and October, 2002 (fig 1). The day of onset was calculated by subtracting the duration of fever from the day of admission. Disease confirmation was by positive microscopic agglutination test (titres above $1 / 100$; 282 of the 340 suspected cases). IgM enzyme linked immunosorbent assay was also positive in 255 of the 282 cases.

The three peaks of disease onset were in August, September, and October. Each of these was preceded by heavy rainfall peaking about 7-10 days previously. Rainfall peaks were followed by rain cessation resulting in troughs in the graph. The baseline of the troughs preceded the disease onset peak by five to six days. The patients did not have direct occupational exposure to animals. Some $62.9 \%$ of the patients had either fissures or wounds on the feet.

Thus, periods of heavy rain followed by days of little or no rain seemed to be the setting for leptospirosis epidemics in this part of the world. Most cases seemed to occur by cutaneous exposure of the legs while walking in stagnant water or moist soil. This implied that leptospira multiplied in the walking paths where water remained undrained for a period of two to three days after the rains was responsible for most cases. Most people in the state wore rubber chappals during the rainy season, which offered little protection against possible infection.

Climatic and environmental factors were probably responsible for epidemic leptospirosis seen in Kerala in the recent years. The pattern of rainfall has changed in the western ghats region of India-which includes Kerala_-in the past century, with more rainless days during the monsoon months. ${ }^{5}$ There had also been rapid urbanisation and construction activities in the past two decades, resulting in blockage of natural drainage of rainwater and consequent water logging near human habitats.

If our hypothesis is correct, future epidemics of leptospirosis can be anticipated by studying daily rainfall patterns. The thrust of community action can then be oriented towards improved water drainage and if necessary by disinfection or salination of water logged walking paths and wearing of effective protective footwear.

M J Pappachan, M Sheela, K P Aravindan Department of Pathology, Medical College, Calicut,

Correspondence to: Professor K P Aravindan, Department of Pathology, Medical College, Calicut 673008, India; kparavind@sancharnet.in

doi: $10.1136 /$ jech.2003.018556

\section{References}

1 Kupek E, de Sousa Santos Faversani MC, de Souza Philippi JM. The relationship between

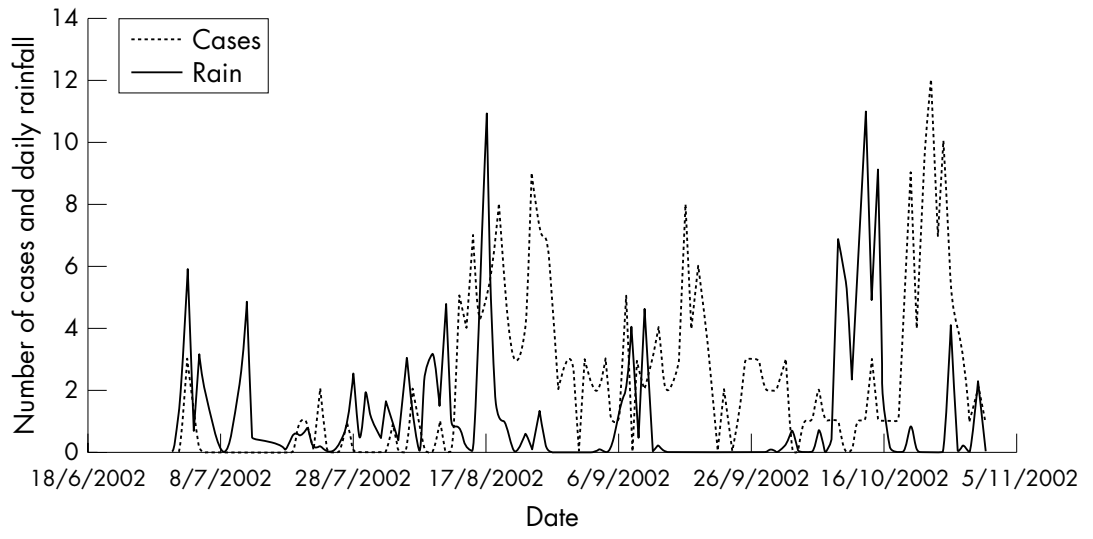

Figure 1 Daily rainfall and leptospirosis incidence (disease onset) for the months July-October 2002. rainfall and human leptospirosis in Florianopolis, Brazil, 1991-1996. Braz J Infect Dis 2000;4:131-4

2 Karande S, Kulkarni $\mathrm{H}$, Kulkarni $M$, et al. Leptospirosis in children in Mumbai slums. Indian J Pediatr 2002;69:855-8.

3 Sanders EJ, Rigau-Perez JG, Smits HL, et al. Increase of leptospirosis in dengue-negative patients after a hurricane in Puerto Rico in 1996. Am J Trop Med Hyg 1999;61:399-404.

4 Perrocheau A, Perolat P. Epidemiology of leptospirosis in New Caledonia (South Pacific): a one-year survey. Eur J Epidemiol 1997:13:161-7.

5 Meher-Homii VM. Probable impact of deforestation on hydrological processes. Climatic Change 1991;19:163-73.

\section{Qualia years $(Q Y)-$ not years - should be the unit of measurement of QALYs, DALYs, life expectancy, and life}

The complementary concepts QALYs and DALYs combine years of life and quality of life in a single measure. ${ }^{1-3}$ In Arnesen and Nord's words: "QALYs are years of healthy life lived; DALYs are years of healthy life lost. Both approaches multiply the number of years ( $\mathrm{x}$ axis) by the quality of those years (y axis). QALYs use "utility weights" of health states; DALYs use "disability weights" to reflect the burden of the same states. If the utility of deafness is 0.67 , the disability weight of deafness is $1-0.67=0.33$. Disregarding age weighting and discounting, and assuming lifetime expectancy of 80 years, a deaf man living 50 years represents $0.67 \times 50=33.5 \quad$ QALYs gained and $0.33 \times 50+1.0 \times(80-50)=46.5$ DALYs lost". ${ }^{2}$ Note that QALYs+DALYs $=33.5+46.5=80.0=$ lifetime expectancy (complementariness).

More accurately, we had to put QALYs $=(0.67) \times(50 \mathrm{y})=33.5 \mathrm{y}$ and DALYs $=$ $(0.33) \times(50 y)+(1.0) \times(80 y-30 y)=46.5 y$. This means that the unit of measurement of QALYs and DALYs is years (y). As $y$ is the unit for lifetime, using the same unit for the product (lifetime) $\times$ (lifequality) is confusing.

Saying that quality is rated on a scale from 0 to 1 , we have implicitly transformed the real but unknown scale of quality into a standard scale, where 0 denotes no quality at all and 1 the $100 \%$ of quality expected (lifequality expectancy). Therefore QALYs and DALYs, combining actual years and dimensionless quality, are, in fact, semistandardised measures. In a previous article we proposed the fully standardised measures SQALYs/SDALYs. ${ }^{4}$ This article, unstandardising lifequality as well, proposes the fully unstandardised measures UQALYs/UDALYs.

Let $\mathrm{q}$ be the unit of measurement of quality - qualio in singular, qualia in plural. Continuing the example above, let us assign lifequality expectancy 160q to dimensionless 1 , and lifequality 107q to 0.67 -in the same manner as dimensionless 1 was previously ${ }^{4}$ assigned to lifetime expectancy and 0.625 to $50 \mathrm{y}$. Thus, fully unstandardised QALYs $=$ UQALYs $=(107 \mathrm{q}) \times(50 \mathrm{y})=5350 \mathrm{qy}$, and fully unstandardised DALYs $=$ UDALYs $=(160 \mathrm{q}-$ $107 q) \times(50 y)+(160 q) \times(80 y-50 y)=7450 q y$. That is, from the total expected life to be lived $=(160 \mathrm{q}) \times(80 \mathrm{y})=12800 \mathrm{qy}=\quad$ life expectancy, 5350qy were actually lived and 
7450 qy were lost: $42 \%$ and $58 \%$ respectively, the same as in fully standardised measures.

These transformed to fully unstandardised measures do not measure life in years as if it was only lifetime, but, as it is the product (lifetime) $\times$ (lifequality), in qualia-years (qy); therefore UQALYs/UDALYs are not misleading. The idea is analogous to py (pack years) in smoking measuring.

Concluding, current semi-standardised QALYs/DALYs should be replaced by either fully unstandardised or fully standardised ones-the latter, in addition, are more understandable and comparable. ${ }^{4}$

loannis D K Dimoliatis

Department of Hygiene and Epidemiology, Medical School, University of loannina, 45110 loannina, Greece; idimolia@cc.voi.gr

\section{References}

1 Murray CJL, Lopez AD. Global burden of disease study. Lancet 1997-349:1269-76, 1347-52, 1436-42, 1498-504.

2 Arnesen T, Nord E. The value of DALY life: problems with ethics and validity of disability adjusted life years. BMJ 1999;319:1423-5.

3 Gold MR, Stevenson D, Fryback DG. HALYs and QALYs and DALYs, oh my: similarities and differences in summary measures of population health. Annu Rev Public Health 2002;23:1 15-34.

4 Dimoliatis ID. Standardised QALYs and DALYs are more understandable, avoid misleading units of measurement, and permit comparisons. J Epidemiol Community Health 2004;58:354.

\section{BOOK REVIEWS}

\section{Archie Cochrane: Back to the front}

Edited by $\mathrm{F} X$ Bosch, R Molas. Barcelona: published privately, 2003.

In 1978 one of the authors of this book (the Catalan epidemiologist Xavier Bosch) and Archie Cochrane (probably one of the most influential personalities in the field of the health care) carried out a journey to the places that the latter knew during the Spanish civil war, as a member of the International Brigades that went to help the Spanish legitimate republican government.

This journey constitutes the starting point of this singular book, carefully edited and illustrated (including some of the legendary photographs of R Capa on the Spanish civil war). To a large extent, the book consists of a series of brief comments (not always laudatory) on the biography of A Cochrane, carried out by epidemiologists as Richard Doll, Peter Elwood, and Lester Breslow, among others. An important part of the text is formed by fragments of well known historians and writers as Gabriel Jackson, Hugh Thomas, and George Orwell, which help to understand the socio-political frame of the Spanish civil war and the second world war, during which he was imprisoned in a Nazi concentration camp (where he could carry out a nutritional clinical trial!). Especially interesting are the comments that connect these first professional experiences with the theoretical thesis that Archie Cochrane would defend later on. We mention, for example the following lines of his autobiography about his clinical practice in the concentration camps, in which it is not difficult to recognise the desire of an evidence based clinical practice:

I remember at that time reading one of those pamphlets considered suitable for POW medical officers about clinical freedom and democracy. I found it impossible to understand. I had considerable freedom of clinical choice of therapy; my trouble was that I did not know which to use and when. I would gladly have sacrificed my freedom for a little knowledge.

The book is conceived as homage to A Cochrane, and does not intend to be either his complete biography, or a critical introduction to his thinking. The book, however, will be read with pleasure by the people that have been felt influenced by the ideas of A Cochrane. On the other hand, young epidemiologists will find in this book, impregnated with social commitment and with ethical values, a superb complement for their career education.

Jaime Latour-Pérez

\section{Global AIDS: myths and facts}

Edited by Alexander Irwin, Joyce Millen, Dorothy Fallows. MA: Cambridge, 2003, \$19.00, pp 296. ISBN 0-89608-673-9

The authors of Global AIDS: myths and facts subtitle their work, Tools for fighting the AIDS pandemic. Indeed, they argue that "informed, determined activism can make a difference" and urge their readers to "get involved in the ongoing effort" to end the AIDS pandemic (page 184). Given this raison d'etre it comes as no surprise that much of their text is devoted to providing practical information that readers can use to educate themselves on a comprehensive array of AIDS issues ranging from vaccine development to drug pricing to organisational corruption as an impediment to expanding HIV prevention and treatment programmes.

At the heart of this volume is a sincere effort to debunk myths and misconceptions that interfere with efforts to systematically and comprehensively tackle the global AIDS epidemic. Readers who are knowledgeable about HIV/AIDS may have difficulty acclimating to the use of "myths" as the unifying construct of the text, as at times, they are, of necessity, overstated (for example, "A vaccine will soon be available to prevent HIV infection", "AIDS is primarily an African problem," etc). Also, one wishes that the editing might have been more careful-a few of the US statistics cited in chapter one are incorrect. For example, it is not accurate that "in 2001 for every AIDS case diagnosed among gay and bisexual men in the U.S. two were diagnosed among heterosexual men or women" (page 14).

In summary, this book provides an accessible overview of the important policy issues facing communities in their struggle to take collective action against AIDS. Readers are provided with informational resources and offered practical recommendations that can help them confront what is undoubtedly the single most important global health crisis of our lifetime. Its message of continued effort in the face of adversity is particularly welcome.

Ronald O Valdiserri

\section{Epidemiologic methods. Studying the occurrence of illness}

Edited by Thomas D Koepsell, Noel S Weiss. Oxford: Oxford University Press, 2003, £39.95, pp 513. ISBN 0-19-515078-3

Several books introducing epidemiology are available. They usually follow the traditional layout: from initial definitions to the description and control of biases and measurement errors and it becomes challenging to offer something "different".

Epidemiological Methods, by Koepsell and Weiss succeeds in presenting epidemiology in a different way. They nicely capture the readers' interest right from the beginning by taking them through a "guided tour" to explore the "epidemic" of retrolental fibroplasia, and its epidemiological investigation that begun in the mid-1940s. The authors present frequency measures, treatments, and results from early studies in descriptive tables and figures, some of which seem contradictory and puzzling. They end up shedding light on the correct interpretation of several years of investigation and controversy. The names of these study designs (cohort, case control, clinical trials, etc) and the reasons why results sometimes seemed contradictory are briefly enumerated and at this point the reader's appetite for more epidemiology increases! One perceives why epidemiology is such a relevant tool.

The classic epidemiological concepts are further on introduced and explained in a very didactic way with real but simple examples that are "beginner friendly" and pertaining mostly to studies that students, novel to this field, will certainly find interesting (AIDS, detection of drinking problems, smoking, etc). Each chapter uses real study examples and 75 figures and 89 tables to boost understanding of difficult issues. At the end of chapters, students can work on exercises that have correct answers and comments. A key asset of this book is that it originates from the teaching experience and materials of the authors. Furthermore, despite being an introductory text, the authors give the reader a flavor of more advanced issues such as residual confounding or interaction. In summary, a nice example of how epidemiology can help students "derive an almost esthetic pleasure from epidemiology".

Jokin de Irala

\section{CORRECTION}

\section{doi: 10.1136/jech.2003.015958corr l}

An editorial error occurred in this paper by Professor Wiggins and others (2004;58:779$87)$. The keys to the symbols in figures 2,3 , and 4 were omitted. In figure 2 diamonds represent employed, squares unemployed, and triangles inactive. In figure 3 diamonds represent previous GHQ 0, crosses previous GHQ 3, and bars previous GHQ 6. In figure 4 diamonds represent previous GHQ 0, crosses previous GHQ 3, and bars previous GHQ 6. 